\title{
Operational Altimeter Sea Level Products
}

G.A. Jacobs, C.N. Barron, D.N. Fox

Naval Research Laboratory. Stennis Space Center, Mississippi USA

This article has been published in Oceanography, Volume 15, Number 1, a quarterly journal of The Oceanography Society. Copyright 2001 by The

Oceanography Society. All rights reserved.

Reproduction of any portion of this article by photocopy machine, reposting, or other means without prior authorization of The Oceanography Society is strictly prohibited. Send all correspondence to: info@tos.org, or 5912 LeMay Road,

K.R. Whitmer

Sverdrup Technology · Stennis Space Center, Mississippi USA

Rockville, MD 20851-2326, USA.

\author{
S. Klingenberger, D. May, J.P. Blaha \\ Naval Oceanographic Office - Stennis Space Center, Mississippi USA
}

Sea level changes observed by satellite altimeter instruments have long been recognized as a vital source for information on open ocean circulation. In a simplified manner, the ocean may be viewed as layers of fluids within which different dynamic processes dominate. Near the ocean surface (within about $30 \mathrm{~m}$, though at times much deeper), fluxes of momentum from wind stress and heat are strong contributors to environmental variations. The rate at which surface fluxes mix into the ocean depends primarily on turbulence generated by wind stress and surface waves. Variations occur on relatively short time periods (on the order of hours to days) in the surface mixed layer. Aside from the mixed layer, the open ocean may be generally viewed as a warm water mass overlying a colder relatively denser water mass. Ocean variations are primarily controlled by changes in the depth of the thermocline, which is the boundary that separates the two water masses. There is a strong correlation between thermocline depth and sea level, which produces a pressure anomaly throughout the water column (see Fox et al., this issue). For example, a relatively high sea level indicates high pressure, and this pushes the thermocline downward.

For the Navy, thermocline variations imply a changed ocean density, which in turn impacts acoustic operations as ocean density controls propagation of sound. A density anomaly between an acoustic source and a sensor may refract sound waves so that the source is not observed. Knowledge of the existence of density anomalies alerts operators to potential acoustically hidden areas.

Open ocean dynamics generating the sea level changes are mainly mesoscale eddies and current meanders. Given an accurate model and accurate forcing (wind stress and heat fluxes), the ocean model will generate mesoscale eddies (see Rhodes et al., this issue). The model may generate eddies with characteristics (size, propagation speed, decay time) similar to observed eddies. However, the mesoscale field is nondeterministic. The model will not generate exactly the same eddy that is observed in the ocean at the same time. Thus, continuous observations of the mesoscale field must be assimilated into numerical models so that the models will represent the synoptic mesoscale field.

The Altimeter Products System (ALPS) is the operational Navy system that provides sea level anomaly observations of the ocean mesoscale to the Navy operational assimilation systems. The Naval Oceanographic Office (NAVOCEANO) is the Navy operational command that gathers altimeter data from available satellites, processes the data, and provides the data operationally. One particular analysis system is the Modular Ocean Data Assimilation System (MODAS) using a 2-dimensional interpolation (MODAS 2-D). MODAS 2-D is designed to provide a rapid analysis capability for the open ocean mesoscale surface structure. The benefit of MODAS 2-D relative to complex numerical models is the reduced computational cost. However, more complete models are expected to produce greater skill in nowcasts forecasts and thus reduce expected errors.

\section{Altimeter Measurement Details}

The altimeter instrument computes range by measuring the round trip travel time of a radar pulse. In addition, the altimeter instrument is able to measure the significant wave height and surface roughness over the radar footprint beneath the satellite from the 
returned radar signal. The surface roughness is related to wind stress. These measurements are of interest for evaluating atmospheric models as well as wave models. NAVOCEANO makes daily comparisons of altimeter wave height information to models and provides the information on the NAVOCEANO web site (www.navo.navy.mil).

The sea surface deviation from its rest state implies a pressure gradient, which in turn controls ocean circulation. The quantity measured by the altimeter instrument is the satellite range $(R)$, which combined with satellite orbital height above the reference ellipsoid $(O)$ provides the sea level height above the reference ellipsoid (SL) (Figure 1)

$$
S L=O-(R+A)
$$

where $A$ represents corrections to the measured range due to atmospheric and other influences. For oceanographic purposes, the sea surface height above the ocean rest state $(S S H)$ is of importance. If $G$ is the geoid height or the distance from the reference level to the geopotential surface followed by the ocean surface if the ocean were at rest and no forcing applied then

$$
S S H=O-(R+A)-G
$$

Often the geoid height is unknown or contains substantial errors. These errors may be avoided by examining only sea level changes from one time to another or deviations from a long time period mean. The sea surface height anomaly (SSHA) is

$$
S S H A=S S H-M D H=S L-(G+M D H)
$$

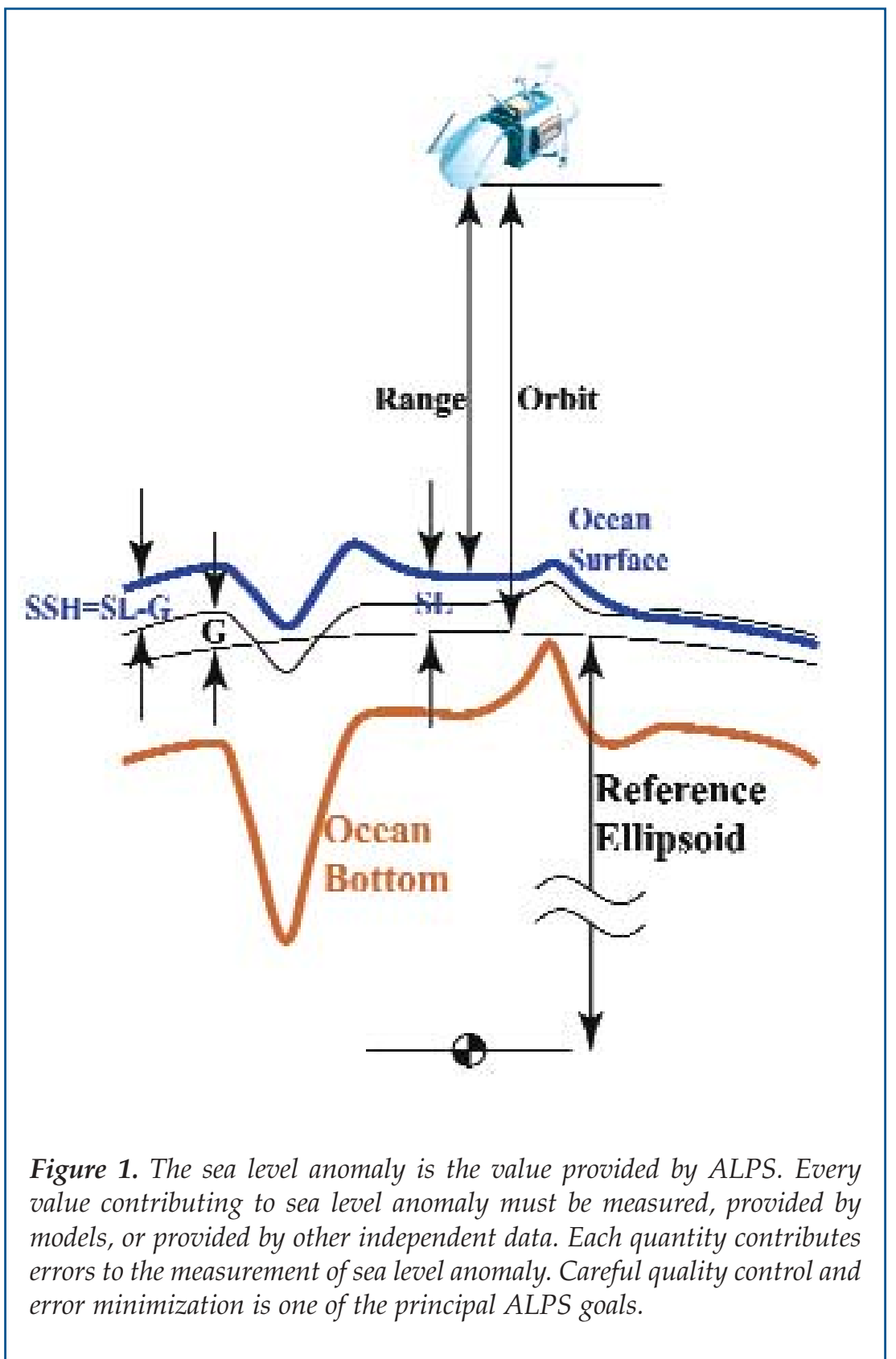

where $M D H$ is the mean dynamic height or height above the geoid due to the time-averaged ocean circulation.

Each of the components needed to determine SSHA is contaminated by errors originating from noise, inaccurate model solutions, and insufficient or inaccurate knowledge. In an operational environment, the errors of each data source must be minimized where possible and the data carefully quality controlled before being used in operational analysis systems.

The satellite altimeter data spectrum of applicability has long been governed by errors from a wide range of sources. Data delivery latency is the factor that distinctly separates altimeter data in the operational environment from the scientific environment. Operational centers provide products that are needed by end users today. In order to maximize data accuracy, science products are able to assemble the best corrections and algorithms years after the original measurements. New understanding, developments, and techniques have allowed significant improvements to data sets that are over 20 years old such as the SeaSat altimeter (Davis et al., 2000). Of course, as scientific developments occur benefits may be realized in operational systems. Operational systems must continually be updated with the latest technology to provide accurate products.

In an environmental prediction system, the output product skill and accuracy are dependent on the input data accuracy. Environmental prediction systems require knowledge of the data accuracy, and this accuracy must be insured when products are delivered to operational sys- 
tems. Data outside expected limits usually cause grave errors in the analysis.

Careful quality control must be implemented to maintain data quality and accuracy. The data processing must also be monitored from beginning to end. On several occasions during the few years that the ALPS system has been operational, singularly unique problems have arisen beyond the control of the ALPS system or the operational center performing the daily processing. One example is the failures of the orientation gyroscopes on the European Earth Remote Sensing satellite (ERS-2) satellite. The satellite was allowed to drift more than $5 \mathrm{~km}$ from its predefined exact repeat track. The large excursions caused large errors due to cross-track geoid gradients. The ERS-2 system output was discontinued until a correction could be implemented based on the mean sea level developed by Smith (1998).

\section{Data Sources}

The Naval Oceanographic Office (NAVOCEANO) at Stennis Space Center, Mississippi, is one of the two main Navy centers for providing operational products (see Burnett et al., this issue). The Altimetry Data Fusion Center (ADFC) at NAVOCEANO has coordinated with NASA to provide for the rapid delivery of TOPEX altimeter data. The TOPEX/POSEIDON (T/P) satellite was launched in August 1992 as a scientific mission to examine ocean tides, ocean basin scale circulation, global sea level rise, and climate change. The GPS receiver onboard the satellite was an experimental system that proved valuable for producing accurate orbit solutions in real time. The Jet Propulsion Laboratory (JPL) provides both the TOPEX instrument data processing and orbit generation in real time for NAVOCEANO. The rapid delivery of data from the European Earth Remote Sensing satellite (ERS-2) is coordinated through the National Oceanic and Atmospheric Administration (NOAA) Laboratory for Satellite Altimetry. The NOAA Laboratory for Satellite Altimetry combines the ERS fast delivery product from the European Space Agency (ESA) with orbit solutions generated by Delft University. The Navy operates the Geosat Follow-On (GFO) altimeter satellite, and the data flows directly to the NAVOCEANO Payload Operations Center (POC). GFO orbit solutions are produced by the Naval Space Operations Command (NAVSOC) based on the Doppler beacon data and by NASA Goddard Space Flight Center, based on laser ranging measurements. The real time delivery of all these data products would not be possible without the extensive coordination between agencies.

NAVOCEANO is actively working to incorporate future altimeter mission data sets as well. The data expected from JASON-1 and ENVISAT will be delivered to NAVOCEANO, ingested into ALPS, and processed along with the other data sets. Beyond these missions, the National Polar-orbiting Operational Environmental Satellite System (NPOESS) is expected to replace the NOAA and DOD polar orbiting satellites with a unified system by 2010, and the ALPS will ingest NPOESS altimeter.

\section{ALPS Quality Control and Error Reduction}

The ALPS processing does not deviate extensively from processing outlined in many previous papers on altimeter data. The altimeter Geophysical Data Records (GDRs) contain the altimeter range measurement, atmospheric corrections, orbit solutions, and subsidiary data from which the $\mathrm{SSH}$ is derived. The atmospheric corrections compensate for the satellite emitted radar pulse propagation speed variations. The corrections include propagation speed changes due to the total dry air mass between the satellite and the subsatellite point (dry troposphere correction), the total precipitable water vapor (wet troposphere), and the total electron count (ionosphere). A correction is also made for the bias of sea level measurement toward wave troughs (electromagnetic bias), which occurs because the wave troughs provide better reflectors than the crests. Each satellite derives corrections from different sources (Table 1), but the sources may be broadly classified into observed or independently modeled.

Corrections based on climatology, numerical models, or models assimilating data are generally free of spurious values and gaps. Observed corrections are provided by sensors onboard the satellite, and spurious values or outliers contaminate these corrections. Outlier detection algorithms must be run on each observed correction, and ALPS checks model-derived corrections for obviously bad values.

The outlier detection of the GDR corrections consists of an along-track data consistency check in which data values are compared to nearby values to insure data consistency. Values not passing this test are flagged as suspect. Each correction is applied to the sea level measurement if the correction is not flagged. If any correction is flagged as bad, the SL measurement is marked with a unique flag identifying the missing correction. At every step through the ALPS processing, if a measurement is found to be bad or suspect, a unique flag is attached to the measurement. Once a measurement is flagged for a particular reason, the flag is not changed again. Thus the final ALPS output contains all the original data including points found to be bad or suspect as well as the flag indicating the reason the data was first flagged.

Such suspect data tracking is useful for system troubleshooting. No system (particularly an operational system) runs without problems for all time. If problems arise, the operational system must provide methods to quickly narrow the scope of troubleshooting. The data users cannot wait long periods of time for extensive troubleshooting to take place. Knowledge of the place in space and time at which data are flagged and the reason for the flagging provides rapid error detection and debugging.

A range of non-mesoscale ocean processes affects SSHA. Within the open ocean, tides are the largest con- 
tributors, which makes them a contaminating signal. Tides are aliased because of the relatively long repeat period of the altimeter satellites (T/P 9.95 days; ERS 35 days; GFO 17.05 days). The $\mathrm{T} / \mathrm{P}$ repeat period was chosen particularly to alias tides to frequencies that are not near the mean, annual, or semi-annual. This allows accurate estimation of tide constituents and insures that the mean, annual, and semi-annual variability are not contaminated by tides. Large improvements have been made in tide solutions using the $\mathrm{T} / \mathrm{P}$ data (Le Provost et al., 1998; Shum et al., 1997; Ray, 1993), and these improved tide solutions are available as corrections to other altimeter data sets. The model presently used in ALPS is the Grenoble FES98.2 (Le Provost et al., 1994) although more accurate tide solutions are presently available. This is an example of one area in which scientific advances improve operational systems, and thus the systems must continually be maintained to improve data accuracy.

Orbit solution errors contribute the largest amplitude and most spatially correlated SSHA errors. Correlated data errors cause problems in environmental assimilation systems since the systems are usually built on the premise that errors between measurements are uncorrelated. Orbit errors are the main difference between operational and scientific data sets because the solution accuracy is strongly dependent on the quantity and quality of satellite position observations available. Not all satellite position measurements can be provided within 24 hours. Real time orbit accuracy (and thus real time altimeter data) has greatly increased due in large part to improved gravity models (Tapley et al., 1994). Correction of residual orbit solution errors is possible because of the unique characteristics of the orbit errors. The orbit errors are predominantly at 1 cycle per satellite revolution (cpr) with smaller amplitudes at 2 cpr.

The orbit error is removed by fitting a sinusoid to the SSHA. Unfortunately, the SSHA contains not only the orbit error, but also real oceanographic features that may appear similar to the functional form used to remove the orbit errors. The main example of this is the global steric anomaly. The global steric anomaly is caused by the asymmetric heating and cooling of the northern and summer hemispheres due to the earth's rotation axis inclination from its orbital plane. The northern hemisphere sea level expands during northern summer at the same time that the southern hemisphere sea level contracts. The opposite situation occurs in northern winter. Suppose we use one satellite revolution of data to estimate a 1 cpr orbit error. When viewed from one satellite revolution of data, the steric anomaly appears very similar to a $1 \mathrm{cpr}$ sinusoid. When using functional forms over data lengths shorter than one satellite revolution, the removal of ocean signal increases dramatically.

Including a climatological sea level in the process of estimating orbit error helps to alleviate the problem of removing ocean signal. The global steric anomaly is relatively regular from year to year, and a reasonable climatology such as GDEM (Teague et al., 1990) captures the seasonal variations relatively well. The orbit

Table 1. The primary real time correction and orbit solution sources used for each satellite system. Corrections derived from models are given in italics. Outliers or spurious values are generally not expected from modeled corrections. Careful outlier editing of observed corrections is made in ALPS. See Rosmond et al. (this issue) for a description of the NOGAPS system.

\begin{tabular}{|l|l|l|l|l|l|}
\hline $\begin{array}{l}\text { Sensor and } \\
\text { GDR source }\end{array}$ & $\begin{array}{l}\text { Dry } \\
\text { troposphere }\end{array}$ & $\begin{array}{l}\text { Wet } \\
\text { troposphere }\end{array}$ & $\begin{array}{l}\text { lonosphere } \\
\text { bias }\end{array}$ & Electro-magnetic & $\begin{array}{l}\text { Orbit } \\
\text { sources }\end{array}$ \\
\hline TOPEX JPL & NOGAPS & $\begin{array}{l}\text { Water vapor } \\
\text { radiometer }\end{array}$ & $\begin{array}{l}\text { Dual frequency } \\
\text { altimeter }\end{array}$ & $\begin{array}{l}\text { Observed wave } \\
\text { height and wind } \\
\text { speed }\end{array}$ & JPL, GPS based \\
\hline $\begin{array}{l}\text { ERS-2 } \\
\text { NOAA }\end{array}$ & NOGAPS & $\begin{array}{l}\text { Water vapor } \\
\text { radiometer }\end{array}$ & Bent model & $\begin{array}{l}\text { Observed wave } \\
\text { height }\end{array}$ & $\begin{array}{l}\text { Delft University, } \\
\text { PRARE-based }\end{array}$ \\
\hline $\begin{array}{l}\text { Geosat } \\
\text { Follow-On } \\
\text { NAVOCEANO }\end{array}$ & NOGAPS & $\begin{array}{l}\text { Water vapor } \\
\text { radiometer }\end{array}$ & $\begin{array}{l}\text { Global } \\
\text { lonosphere } \\
\text { Maps }\end{array}$ & $\begin{array}{l}\text { Observed wave } \\
\text { height }\end{array}$ & $\begin{array}{l}\text { NAVSOC, } \\
\text { Doppler beacon } \\
\text { based; NASA, } \\
\text { laser ranging } \\
\text { based }\end{array}$ \\
\hline
\end{tabular}


error is estimated by minimizing the SSHA minus climatological dynamic height anomaly for the same time of year.

One of the most important aspects of ALPS is consistency. All altimeter data sets must be treated as equally as possible (even though they are quite unique) in order to insure errors in the data sets are as uniform as possible. In addition, each satellite SSHA must be a deviation from consistent $M D H$. We are not able to compute the $M D H$ directly from the altimeter data, but we can compute the geoid plus the $M D H$ over the time period of each satellite directly from each satellite data set. Simply averaging the provides this. However, this would produce a $M D H$ relative to a different time period for each satellite, and consistency would be lost. The methods we use to generate $S S H A$ relative to a consistent time period for ERS are outlined in Jacobs et al. (2001). The mean sea level used for GFO is based on the Geosat-ERM data, and the methods used to derive a consistent mean for this data set are described in Jacobs and Mitchell (1997).

The overall real time system accuracy is measured by crossover analysis, which examines the sea level at points where ascending and descending ground tracks cross one another. At these points, the SSHA should be the same between ascending and descending passes if the ocean circulation were not to change. The further the temporal separation between the crossover measurements, the greater the influence of oceanographic changes might be. In spite of this concern, the crossover analysis provides a good measure of overall system accuracy, which includes accuracy of all atmospheric corrections, orbit solutions, tide solutions, and mean sea levels added together. The RMS crossover differences (Table 2) for each satellite and between the different satellites (at points where one satellite ground track crosses another) indicate the noise level of each system. The RMS noise of each altimeter would be the diagonal values divided by the square root of 2 . Thus the noise

Table 2. The RMS crossover difference (cm RMS) for each satellite and between the satellites is computed using 20 days of data from May 18 through June 7, 2001. All data between $65^{\circ} \mathrm{S}$ and $65^{\circ} \mathrm{N}$ are included (there is no cutoff based on ocean depth).

\begin{tabular}{|l|l|l|l|}
\hline & TOPEX & ERS & GFO \\
\hline TOPEX & 7.85 & & \\
\hline ERS & 11.01 & 12.51 & \\
\hline GFO & 9.80 & 12.45 & 10.83 \\
\hline
\end{tabular}

level of TOPEX is $5.5 \mathrm{~cm}$, ERS is $8.8 \mathrm{~cm}$, and GFO is 7.7 $\mathrm{cm}$. TOPEX is the most accurate altimeter system to date, and the real time RMS error here is close to the level reported by $\mathrm{Fu}$ et al. (1994) of $5.1 \mathrm{~cm}$. The crossovers between GFO and TOPEX are consistently less than those between ERS and TOPEX, indicating that GFO is more accurate or that the errors in GFO are more consistent with those in TOPEX. The output along track for one particular day (Figure 2) indicates similar features in all three altimeter data sets.

\section{MODAS Interpolation}

The along track SSHA from ALPS is provided to MODAS 2-D, which uses an optimal interpolation (OI) procedure (Bretherton, 1976) to generate a rapid mesoscale ocean product. The optimal interpolation is strongly dependent on the covariance function, which describes how SSHA at one point in space and time is related to SSHA at another point in space and time. This information is extremely important for computing SSHA at points that are far from the satellite ground tracks. Ocean eddies generally have length scales from 20 to $100 \mathrm{~km}$. Providing a synoptic picture of the ocean eddy field would not be possible using only the data of a single altimeter satellite and is only marginally possible with three (Jacobs et al., 2001). An eddy may happen to be located along one satellite ground track at one time, but will gradually propagate away from the ground track. Some additional information is needed to help provide SSHA estimates away from ground tracks, and this information is embodied in the OI covariance functions or the numerical model dynamics into which the data is assimilated.

The characteristic propagation speeds, length scales, and time scales provide this extra information. These quantities have been observed by in situ instrumentation as well as estimated from historical altimeter data directly. Presently MODAS 2-D uses the mesoscale characteristics computed throughout the globe by Jacobs et al. (2001). The spatial and temporal scales as well as propagation speeds are determined by fitting a Gaussian functional form to the binned observed covariance functions based on the historical GeosatERM, T/P, ERS-1, and ERS-2 data sets.

In addition to estimating the SSHA, the OI process provides an estimate of the analysis error. This error depends on the covariance function, and since MODAS 2-D uses a relatively realistic mesoscale covariance function it provides an estimate of the error in each satellite's ability to measure the mesoscale field. The SSHA output by MODAS 2-D and the expected error field is quite different if each data set is used individually as opposed to using all the data sets together (Figure 3 and Figure 4). The TOPEX expected error is 


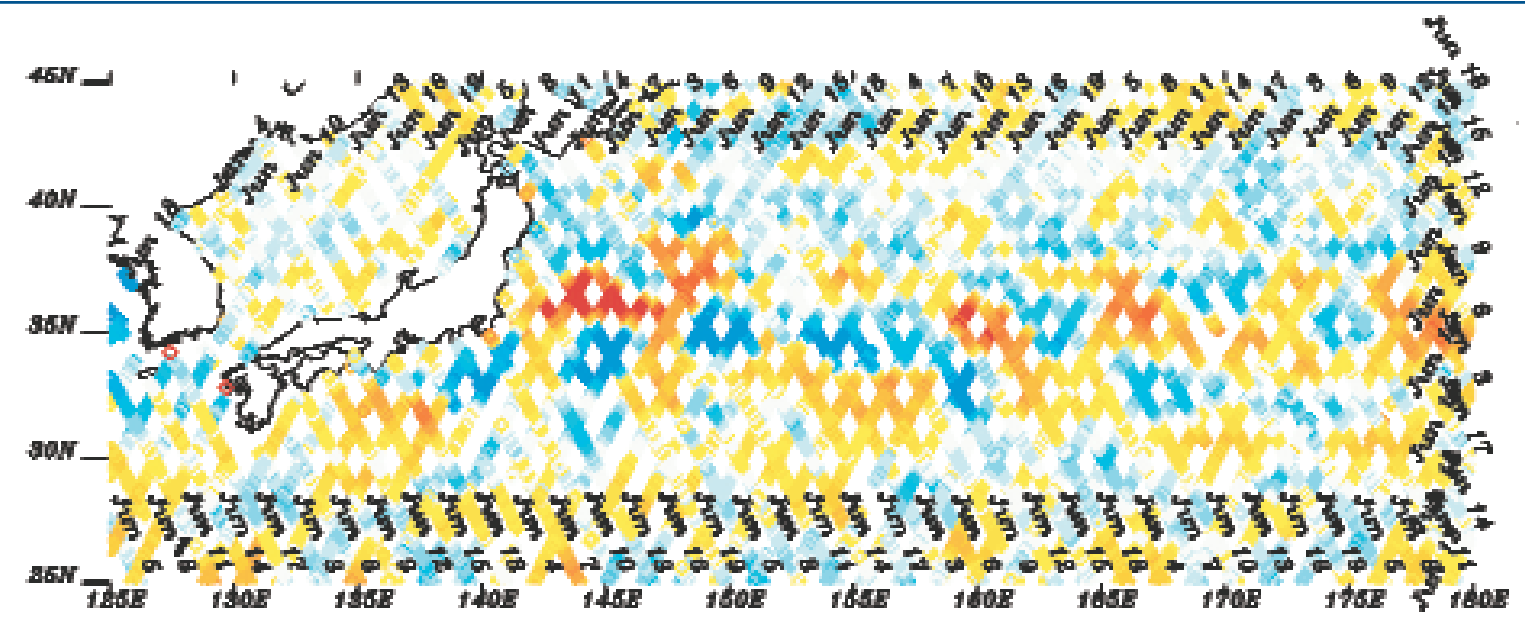

Mont rwoent datar 80 June 2001 0.00 Gar

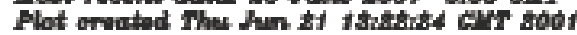

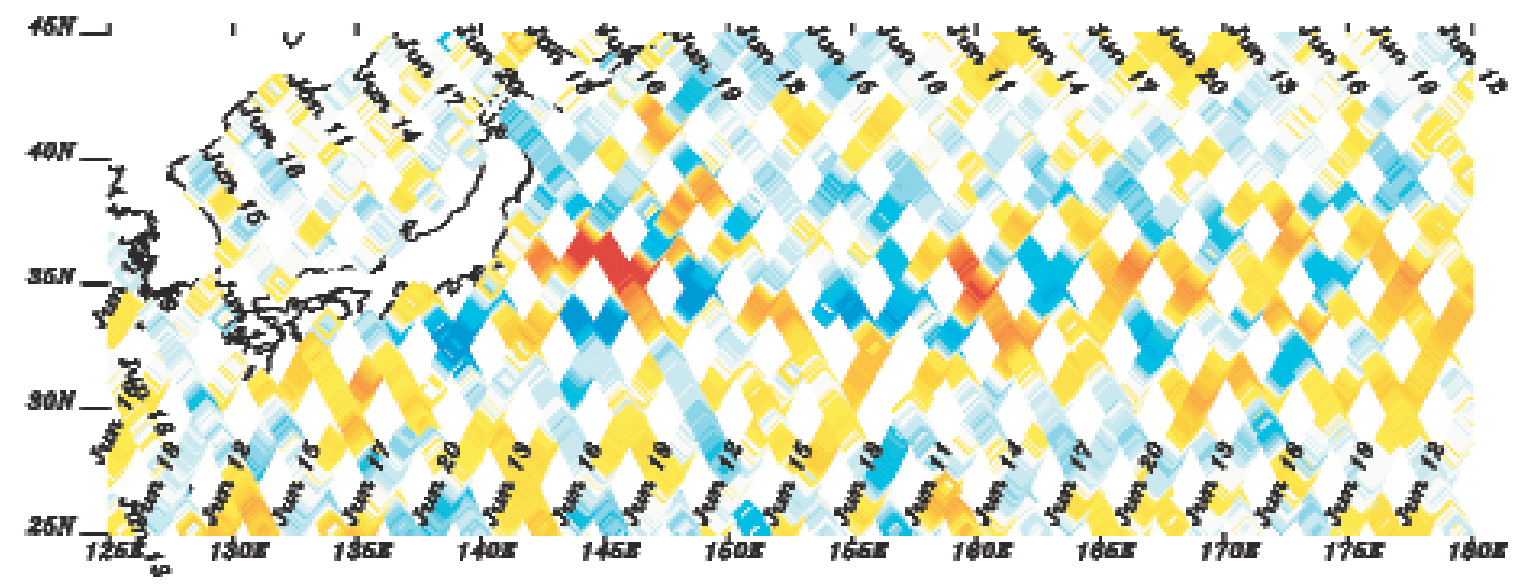

Mant resent data: 20 June 2001 28:68 $\mathrm{cur}$

Plot orvated That Rar 21 14:56,52 CarT 2001

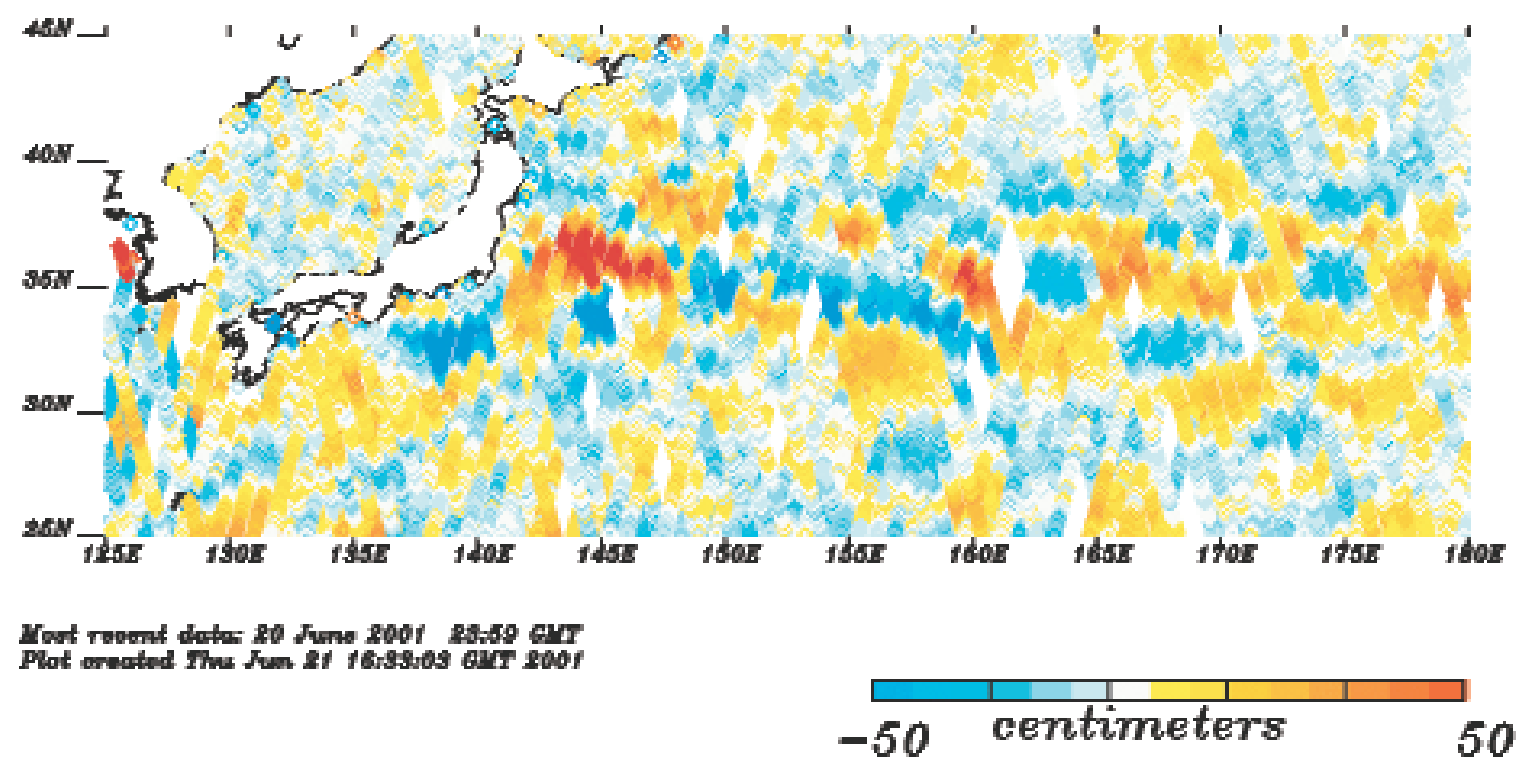

Figure 2. The along-track SLA output by ALPS in the Kuroshio Extension region for each of the three altimeter data sets (top: GFO, middle: TOPEX, bottom: ERS) indicate the same features. One cycle of data is plotted for each altimeter. 

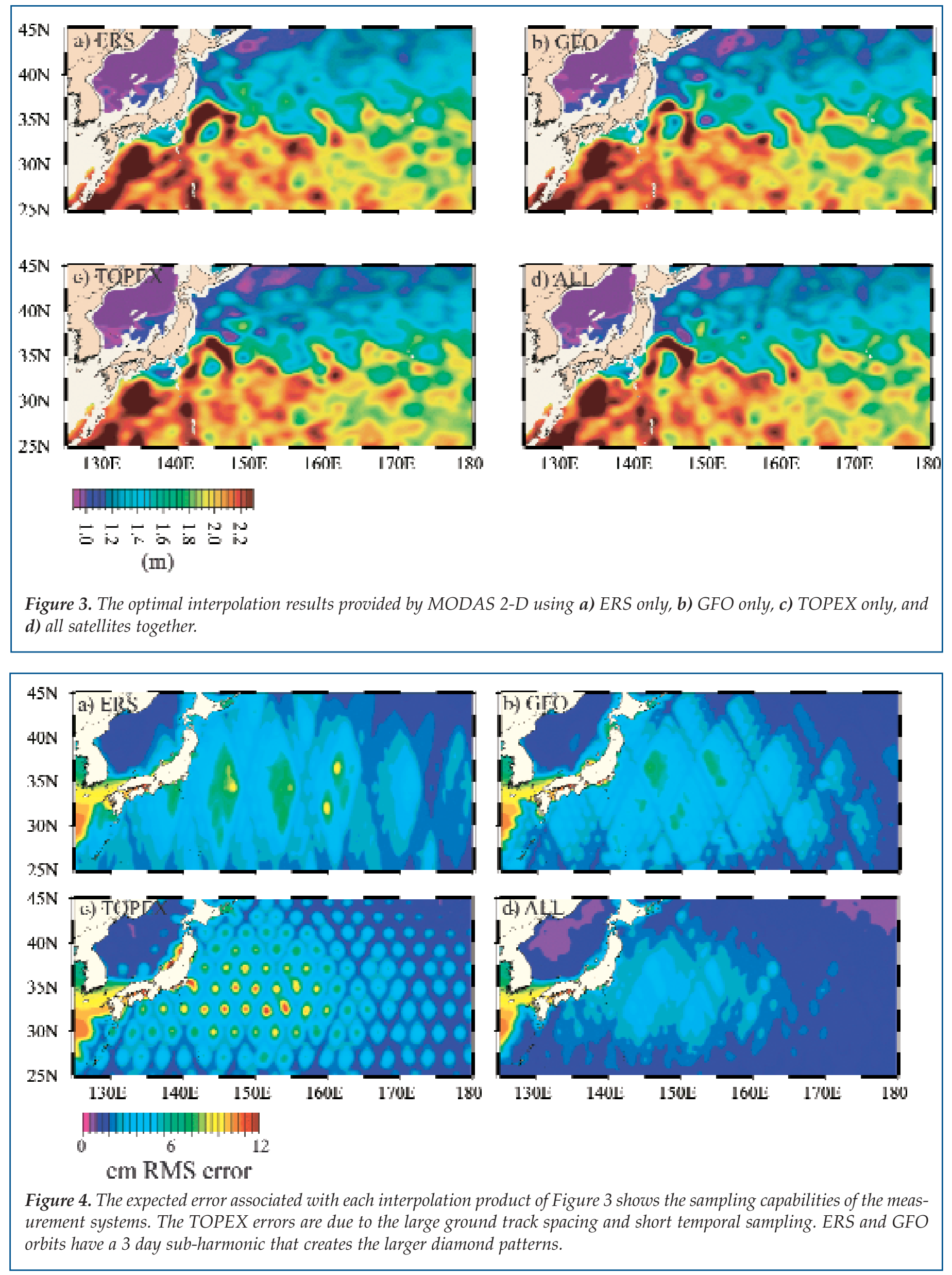

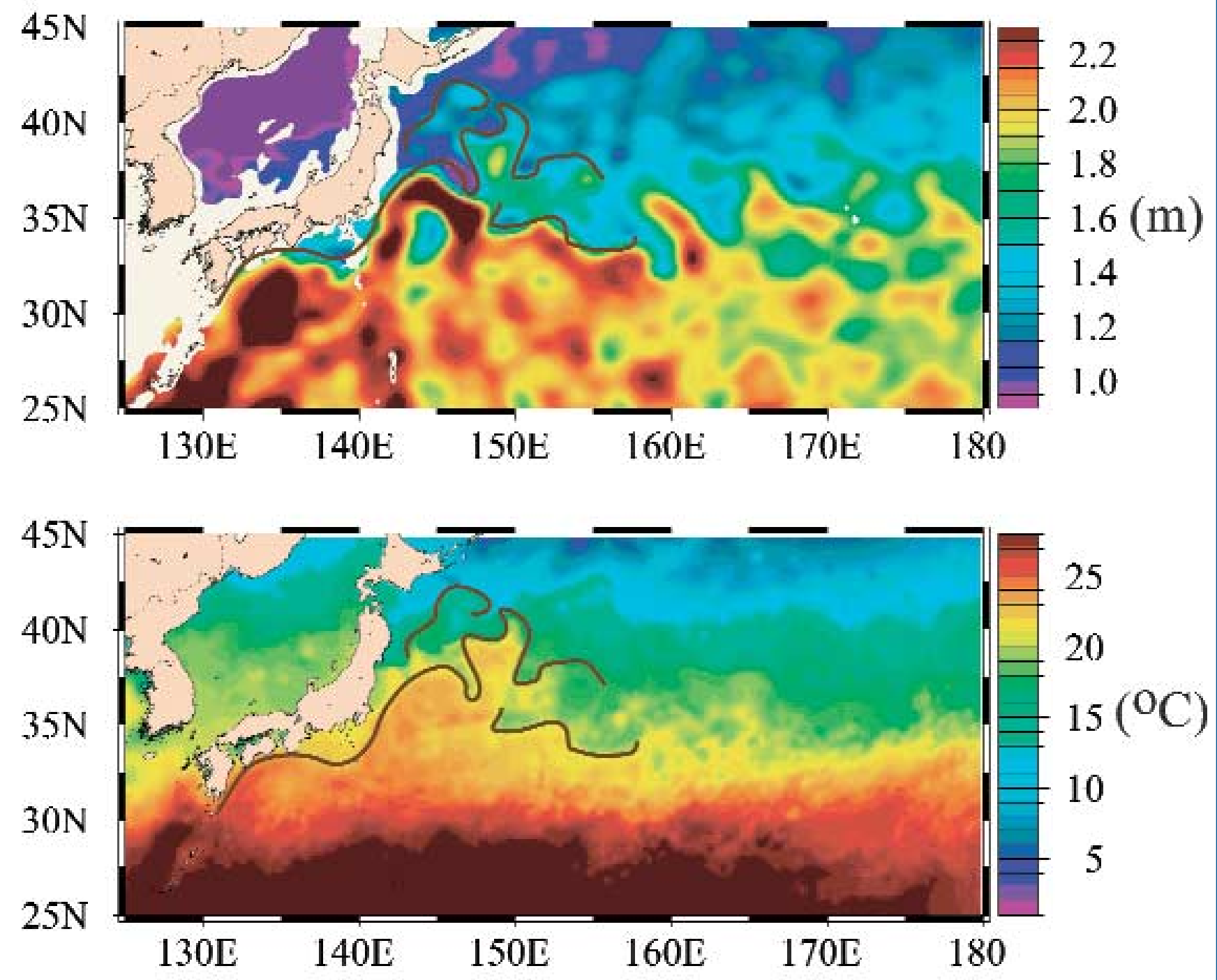

Figure 5. (top) The output by MODAS 2-D plus a climatological mean dynamic height relative to $1000 \mathrm{~m}$ provided by the MODAS climatology is compared to (bottom) the sea surface temperature during the same time. The subjective frontal position lines in each plot are in the same position. There is a good correspondence between temperature fronts and sea level features. The advection of the temperature field is controlled by the geostrophic currents associated with the pressure gradients caused by the sea level.

relatively small along ground tracks due to the higher data accuracy as well as the frequency of measurement (9.95 days). However, between ground tracks errors are expected to be large because the mesoscale length scales (about $100 \mathrm{~km}$ in the Kuroshio) are much smaller than the ground track spacing (about $260 \mathrm{~km}$ at $35^{\circ} \mathrm{N}$ ). The expected errors of GFO and ERS are generally more uniform than TOPEX. The ground track spacing of these satellites is smaller $(125 \mathrm{~km}$ for GFO and $65 \mathrm{~km}$ for ERS at $35^{\circ} \mathrm{N}$ ) than TOPEX with longer repeat periods (17.05 days for GFO and 35 days for ERS). Using all three satellites together reduces the error levels computed by the optimal interpolation.
One example of the MODAS 2-D interpolated SSH and interpolated SST (Figure 5) indicates the good correspondence between the eddy and meander positions of the Kuroshio. The altimeter provides only the SSHA. To generate total SSH an MDH must be added to SLA. The $M D H$ is derived from the climatological dynamic height relative to $1000 \mathrm{~m}$ using the MODAS climatology.

\section{Continuation}

A conclusion to this article would imply an end. However, the altimeter products will continue to flow from the ADFC, and ALPS will continually be main- 
tained and upgraded. Thus we provide an outlook for the future.

All the data products described here are publicly available in real time on "The Real Time Ocean Environment" web page (http://www7300.nrlssc.navy.mil/altimetry). Every day, the ALPS and MODAS 2-D analyses are run on the previous 60 days of altimeter data. The reason for rerunning 60 days of data every day is to allow for data transmission problems that may delay data delivery. The along-track SSHA output by ALPS is processed and displayed daily along with the MODAS 2-D SSHA analysis throughout the globe.

However, we should never take it for granted that a measurement system will continue to perform at its present levels without problems. The principal ALPS goals are not only to provide as accurate data as possible but also to provide continuous monitoring of the data and rapid alerts to any problems. To this end, all flagged points for each altimeter, orbit corrections applied, crossover RMS, and fraction of possible data found to pass the quality control procedures are updated daily on the web. These tools allow operators to continuously monitor the real time data streams and correct any problems quickly without significant interruption to the operational products.

For the future, the system will be maintained as part of the continuing Navy operational capabilities. ALPS will integrate new data streams from the planned JASON-1 and ENVISAT missions as well as NPOESS. Presently several enhancements are planned for transition to the system, and as has been the case for many years continued understanding of the altimeter system and corrections provide further advances in data accuracy. These changes are introduced primarily to support greater accuracy for the MODAS and numerical model systems using the ALPS output. Since the origination of ALPS, these enhancements have increased the ocean environment estimation accuracy, and continued enhancements will further improve the accuracy.

\section{Acknowledgments}

This work was sponsored as part of the NRL 6.4 Altimeter Data Fusion Center Support project, managed by the Space and Naval Warfare Systems Command under program element 0603207N. The operational altimeter data would not be possible without the combined work of many people in many groups including NASA, the Jet Propulsion Laboratory, Goddard Space Flight Center, the National Oceanic and Atmospheric Administration, the European Space Agency, the Colorado Center for Astrodynamics Research, the University of Texas Center for Space Research, and Ohio State University to name just a few.

\section{References}

Bretherton, F.P., R.E. Davis and C.B. Fandry, 1976: A technique for objective analysis and design of oceanographic experiments applied to MODE-73.
Deep Sea Res., 23, 559-582.

Davis C.H., C.A. Kluever, B.J. Haines, C. Perez and Y.T. Yoon, 2000: Improved elevation-change measurement of the southern Greenland ice sheet from satellite radar altimetry. IEEE Trans. Geosci. and Remote Sens., 38, 1367-1378.

Fox, D.N., M.R. Carnes, C.N. Barron, G. Peggion and J.V. Gurley, this issue. The modular ocean data assimilation system.

Fu, L.L., E.J. Christensen, C.A. Yamarone, M. Lefebvre, Y. Menard, M. Dorrer and P. Escudier, 1994: TOPEX/POSEIDON mission overview. J. Geophys. Res., 99, 24,369-24,382.

Jacobs, G.A. and J.L. Mitchell, 1997: Combining multiple altimeter missions. J. Geophys. Res., 102, 23,187-23,206.

Jacobs, G.A., C.N. Barron and R.C. Rhodes, 2001: Mesoscale characteristics. J. Geophys. Res., 106, 19,581-19,595.

Le Provost, C., M.L. Genco, F. Lyard, P. Vincent and P. Canceil, 1994: Spectroscopy of the world ocean tides form a finite element hydrodynamic model. $J$. Geophys. Res., 99, 24,777-24, 798.

Le Provost C., F. Lyard, J.M. Molines, M.L. Genco and F. Rabilloud, 1998: A hydrodynamic ocean tide model improved by assimilating a satellite altimeter derived data set. J. Geophys. Res., 103, 5513-5529.

Ray, R.D., 1993: Global ocean tide models on the eve of TOPEX / POSEIDON. IEEE Trans. Geosci. and Rem. Sens., 31, 355-364.

Smith, W.H.F., 1998: Seafloor tectonic fabric from satellite altimetry. Ann. Rev. Earth and Planetary Sci., 26, 697-747.

Shum C.K., P.L. Woodworth, O.B. Andersen, G.D. Egbert, O. Francis, C. King, S.M. Klosko, C. LeProvost, X. Li, J.M. Molines, M.E. Parke, R.D. Ray, M.G. Schlax, D. Stammer, C.C. Tierney, P. Vincent and C.I. Wunsch, 1997: Accuracy assessment of recent ocean tide models. J. Geophys. Res., 102, 25173-25194.

Tapley, B.D., J.C. Ries, G.W. Davis, R.J. Eanes, B.E. Shutz, C.K. Shum, M.M. Watkins, J.A. Marshall, R.S. Nerem, B.H. Putney, S.M. Klosko, S.B. Luthcke, D. Pavlis, R.G. Williamson and N.P. Zelensky, 1994: Precision orbit determination for TOPEX/POSEIDON. J. Geophys. Res., 24383-24404.

Teague, W.J., M.J. Carron and P.J. Hogan, 1990: A comparison between the Generalized Digital Environmental Model and Levitus climatologies. J. Geophys. Res., 95, 7167-7183. 